Bol. Acad. peru. leng. 48. 2009 (139-156)

\title{
EL ÁNGEL DE LA MELANCOLÍA. SOBRE RAFAEL ALBERTI Y LA POESÍA DEL EXILIO
}

\author{
Marco Martos Carrera \\ Academia Peruana de la Lengua
}

Fecha de recepción:

$20 / 07 / 2009$

Fecha de aceptación:

$10 / 10 / 2009$

Sabido es que, aunque poco lo meditamos, la vida entera de los seres humanos está signada por las separaciones, desde el claustro materno, hasta la muerte. Poco se ha advertido, salvo en el caso de la psicología, que esas rupturas, siendo dolorosas, permiten crecer a los individuos, madurar y también ganar experiencias valiosísimas, imposibles de obtener si permanecieran en lo propio y conocido.

Como es de suponer, los artistas, y, de modo especial, los poetas, esos barómetros de la más depurada sensibilidad, son los que registran mejor ese sufrimiento por dejar atrás lo conocido, ese azoramiento, esa perplejidad y ese encanto que provocan las situaciones nuevas.

Ya desde sus primigenios poemas, aquellos de Marinero en tierra, que fueron distinguidos en 1924 con el premio nacional de Literatura de España, por un exigente jurado del que formaba parte Antonio Machado, Rafael Alberti expresó la nostalgia de quien se separa de lo querido. Son 
versos premonitorios de los duros exilios que atravesarían buena parte de su vida, hasta 1977, cuando al fin pudo regresar definitivamente a su patria. En aquella ocasión se trataba de un marinero, alejado, desterrado de su mar de Cádiz:
El mar. La mar.
El mar ¡Sólo la mar!

¿Por qué me trajiste padre, a la ciudad?

¿Por qué me desenterraste del mar?

En sueños, la marejada me tira del corazón.

Se lo quisiera llevar.

Padre ¿por qué me trajiste acá?

Este primer exilio, impuesto por las circunstancias, esta separación forzada es como un río subterráneo que atraviesa casi toda la obra inicial de Alberti y confiere una nota de honda seriedad, inclusive a sus poemas más alegres. No es sorprendente que en su segundo libro La amante de 1925, el poeta no deje de ser un marinero en tierra y les diga a los castellanos del Duero, que viven ensimismados en su querencia:

¡Castellanos de Castilla

Nunca habéis visto la mar!

¡Alerta que en estos ojos

del sur y en este cantar

yo os traigo toda la mar!

¡Miradme que pasa el mar!

tal vez como respuesta a aquel "No puede ver el mar la vieja Castilla" que había escrito antes Azorín. 
Esta inicial imagen, repetida con infinidad de variaciones, confiere a la poesía de Alberti un halo de nostalgia que se conservará a lo largo de una actividad intensa y vasta. Pero el vate no es alguien que se solace en los reconcomios de la tristeza y que permanezca en duelo permanente por el bien perdido. Más tarde se convertiría, en lo que él mismo denominó "poeta de la calle". Justamente Poeta en la calle (1931-1935) es el primer libro de poesía netamente comprometida que escribiría Alberti en estos años. Pero ese traslado de un yo individual a un yo social, no ocurre de un momento a otro. Antes, el lírico sufre un proceso de interiorización de lo nuevo, que inevitablemente pasa por una comparación con aquello distinto que iba conociendo, la meseta castellana, pero que venía, en cierta medida, impuesto por ajena voluntad, tanto por el padre que deseaba una recuperación para el poeta que tenía la salud quebrantada, como por la enfermedad, que imponía sus propias reglas. Y aunque eso no aparezca en los poemas, está en los escritos en prosa y en las biografías del escritor. Pergeñó entonces Alberti este poema:

\section{De Burgos a Villarcayo}

Castilla tiene castillos, pero no tiene una mar. Pero sí una estepa grande, mi amor, donde guerrear. Mi pueblo tiene castillos, pero también una mar, una mar de añil y grande, mi amor, donde guerrear.

No sabía entonces, no podía saberlo, que más adelante su nostalgia de Cádiz iba a ser nostalgia de España y que iría por el mundo como uno de los más conspicuos representantes de la lengua castellana.

Conocido es que los poetas llamados de 27, entre los que estaban Federico García Lorca y Rafael Alberti, mantuvieron en sus comienzos una relación de admiración y de respetuosa amistad por los líricos de la generación del 98. Ahora mismo suele incluirse en la edición de las poesías 
completas de Alberti, una carta que le dirigió el lírico de Moguer el 31 de mayo de 1925 en la que como un hermano mayor le dice una serie de elogios a Marinero en tierra y que terminan con las siguientes palabras: "Enhorabuena y gracias de su amigo y triple paisano: por tierra, mar y cielo del oeste andaluz". De esa relación queda en la memoria en la traviesa pluma del propio Alberti, el relato de las visitas que hacían los jóvenes poetas al que más tarde se llamaría el andaluz universal. Jiménez era muy celoso de su tiempo y concedía una relativa importancia a los vates en agraz. Cuando ellos lo visitaban de manera inopinada, se escuchaba su voz aguda, bajando la escalera: “Juan Ramón Jiménez no está". Los muchachos del 27 lo tomaban a broma y no cejaban en su empeño. De cuando en cuando Jiménez los recibía y la charla se hacía interminable.

En una ocasión, para evitar la negativa del poeta de Moguer, aprovechando que la puerta estaba entreabierta, Alberti y sus cófrades, subieron la escalera a trancos y se instalaron en la salita del poeta. Zenobia, la esposa del más tarde Premio Nóbel de Literatura, tuvo que salir para decir la consabida mentira piadosa: "Juan Ramón Jiménez no está". Entonces Alberti dijo: "No importa, lo esperaremos". La dama no supo qué hacer y se retiró discretamente. Todos sabían, por supuesto, que Juan Ramón Jiménez se hallaba en las habitaciones interiores. Nos lo imaginamos hirviendo de cólera por el atrevimiento de sus jóvenes admiradores. Pasaron varios minutos, pronto transcurrió y los inoportunos visitantes no daban señas de querer marcharse. De pronto Juan Ramón tuvo necesidad de un libro que se hallaba en la salita. Tomó un biombo y, como en una obra de teatro, avanzó resueltamente hasta el estante, escogió el libro que buscaba y se retiró dando pasos para atrás, en medio del desconcierto de los fallidos contertulios que aun reconociendo los pies del ilustre poeta tuvieron que rendirse ante semejante artilugio de Jiménez que con este procedimiento de estrategia teatral obtuvo una victoria definitiva. Los vates se retiraron en tropel.

Algunos años más tarde, en ese clima de tensión que precedió a la guerra civil, cuando Juan Ramón Jiménez urbi et orbi había difundido su teoría de la poesía pura y la necesidad de escribir para las minorías selectas 
o, concediendo, para la inmensa minoría, Rafael Alberti escribió una de las páginas más duras contra él en la que le reprochaba que se detuviera en los colores rosas, malvas, azules de su jardín, mientras el destino de España se decidía en las calles. Y es que Jiménez, de un temperamento bastante nervioso, pasó algún tiempo en casas de reposo. Poco se ha meditado, en el desgarrón interno de Alberti en estos años, cuando por libre elección y de un modo combativo, escoge la defensa de la república amenazada. Entre los antagonistas había personas por las que había sentido afecto, y entre quienes preferían no tomar partido, había otros a los que apreciaba, pero él rompió con todos, como ocurrió con Jiménez como antes hemos narrado. Un cuchillo homicida desgarró en dos a España y pasaron décadas antes de que sanaran las profundas heridas. Alberti quedó maltrecho como tantos otros y como lo ha recordado en La arboleda perdida, salió milagrosamente de su patria en los primeros días de marzo de 1939, camino de Orán, desde donde pudo trasladarse a París. En la metrópoli francesa trabajó como locutor de Radio París y empieza a escribir la primera parte de sus memorias. ¿Quién empieza sus memorias antes de los cuarenta años? Alguien que tiene mucho que recordar y que quiere dejar constancia de que ha vivido.

Sus poemas de aquel corto periodo tienen las primeras marcas del destierro verdadero. Recuerdos de guerra, de parajes de España, del Museo del Prado. Hay mucha amargura cuando acusa a Francia y a otros países europeos de haber dejado sola a España. "Il ne faut pas oublier / que vous étes un pauvre emigre" dice. El poeta quiere otra cosa. Se despide de la niebla de Francia y del sol de España. Mira a América esperanzado y escribe:

Bajo la Cruz del Sur cambiará nuestra suerte.

América.

Por caminos de plata hacia ti voy

a darte lo que hoy

un poeta español puede ofrecerte. 
Naturalmente no se trata de de un proceso lineal, el poeta tiene nostalgia de sus parajes queridos, lleva, para usar una frase de Neruda, a España en el corazón y estará con ella toda la vida. Entonces escribe uno de los más hermosos poemas salidos de su pluma:

19

(Muelle del reloj)

A través de una niebla caporal de tabaco

miro al río de Francia

moviendo escombros tristes, arrastrando ruinas

por el pesado verde ricino de sus aguas.

Mis ventanas

ya no dan a los álamos y los ríos de España.

Quiero mojar la mano en tan espeso frío

y parar lo que pasa

por entre ciegas bocas de piedra, dividiendo

subterráneos y cloacas.

Mis ventanas

ya no dan a los álamos y los ríos de España.

Miro una lenta piel de toro desollado, sola, descuartizada, sosteniendo cadáveres de voces conocidas, sombra abajo, hacia la mar, hacia una mar sin barcas.

Mis ventanas ya no dan a los álamos y los ríos de España.

Desgraciada viajera fluvial que de mis ojos desprendidos arrancas

eso que de sus cuencas desciende como río cuando el llanto se olvida de rodar como lágrima.

Mi ventanas

ya no dan a los álamos y los ríos de España. 
Cuando Rafael Alberti llega a la Argentina, en 1940, acompañado de su esposa María Teresa León que tanta importancia tuvo en su creación literaria, fue recibido fraternalmente por muchos personajes del ambiente cultural y especialmente por Gonzalo Losada. El poeta escoge como lugar de residencia a Córdoba, y un año después Losada le publicó Entre el clavel y la espada que reunía poemas de 1939 y 1940. Allí escribió en el pórtico:

\section{DE AYER PARA HOY}

Después de este desorden impuesto, de esta prisa, de esta urgente gramática necesaria en que vivo, vuelve a mí toda virgen la palabra precisa, virgen el verbo exacto con el justo adjetivo.

Que cuando califique de verde, al monte, al prado, repitiéndole al cielo su azul como a la mar, mi corazón se siente recién inaugurado y mi lengua el inédito asombro de crear.

Conviene detenerse en esta confesión poética. Atrás han quedado las tensiones de España, las angustias de la guerra civil. En el sentido más estricto Alberti es un sobreviviente. Muerto está Lorca desde 1936, muerto está Machado desde 1939, muertos o en prisión están tantos otros compañeros como Miguel Hernández, que desaparecería en 1942. Habían sido muy duros todos esos años. Buena parte de la poesía escrita por los mejores poetas, como aquella publicada en la revista "El mono azul" había sido no solamente una lírica comprometida, sino de circunstancias, una escritura que mostraba ya poca capacidad de resistir el paso del tiempo y que bastante pronto evidenciaba su apresuramiento. Alberti no había escapado a esa tentación, a ese facilismo, aunque su gran calidad salva inclusive algunos versos de ocasión, recuperando la musa esperpéntica de Quevedo como ocurre con un poema dedicado en 1938 a un cónsul español afincado en la ciudad mexicana de Tampico:

Un gargajo sin sal mal expedido, un esputo esputado de una puta, 
una tuerca acabada en cagarruta, un pedo consular ya dimitido.

Un gancho del revés, digo, invertido, una bisagra puesta a una viruta, una batuta rota, una batuta bailando al son de un asno retorcido.

Un tornillo monárquico clavado a una muerta República a quien roba, difama y lame con traidor de hocico.

Un cabrón, un marica, un esmirriado, un manojo de cerdos, una escoba para hurgar los retretes de Tampico.

En Argentina el poeta está en capacidad de voltear una página dolorosa, aunque sufriendo hincones. El texto que abre Entre el clavel y la espada nace de los entresijos del ser. El poeta reconoce que el desorden social ha impuesto su propia lógica, pero, aparte, toma el pulso a la prisa de su vida, a la urgente gramática necesaria en que vive, y que no es otra que su compromiso, como escritor y como artista con el pueblo, pero todo eso conduce a que vuelve a él "toda virgen la palabra precisa, virgen el verbo exacto con el justo adjetivo" con lo que termina en el plano poético por reconciliarse de algún modo con la estética de Juan Ramón Jiménez.

Sin embargo:

Duras, las tierras ajenas.

Ellas agradan los muertos, ellas.

Triste, es más triste llegar que lo que se deja.

Ellas agrandan el llanto, ellas. 
Estos versos de Entre el clavel y la espada hablan del Mío Cid. El atento lector puede percibir en la entrelínea el matiz autobiográfico.

El primer libro que escribiría Alberti totalmente en América será Pleamar, pergeñado entre 1942 y 1944. Entre el clavel y la espada fue redactado en París y en medio del Atlántico, viajando, como diría más tarde, en 1967, hacia el destierro argentino. En París el poeta había estado de paso, en el desasosiego de lo indefinido, ignorando a ciencia cierta la naturaleza de su destino, sin desprenderse totalmente de los duros acontecimientos españoles, viviendo la vida bilingüe de un desterrado español, con la rosa de los vientos no a su disposición como sueñan los poetas, sino con voluntad de llevarlo a cualquier parte, a México por ejemplo, acompañando a José Berjamín a quien evoca en uno de sus versos; cierto que México resultó una excelente patria para tantos republicanos españoles, pero la caprichosa rosa pudo conducirlo quién sabe adónde. Felizmente llegó a Argentina, país que pasaba por un momento privilegiado de su desarrollo cultural, tanto por razones históricas, como por desarrollo interno propicio a las artes y las letras. Junto con Alberti, muchos otros escritores europeos, entre ellos Witold Gombrowitz, escogieron Buenos Aires como un destino. En Argentina Alberti volvió a encontrarse con su idioma, verdad que la variante hispanoamericana del Río de la Plata que tanto nos cuesta aceptar a quienes no somos ni argentinos ni uruguayos, pero fue también la oportunidad de hablar español en la calle, de asimilar neologismos, de recordar vocablos que en la península son arcaísmos o palabras desaparecidas. Uno de los mejores amigos de Alberti en su periodo argentino fue el editor Gonzalo Losada, a quien tanto le deben las letras de nuestros países. Sin Losada, es inimaginable la vasta difusión de la literatura hispanoamericana entre los años cuarenta y setenta. Hizo ediciones modernas de los clásicos, auspició a los autores más conocidos del momento y apostó por los nuevos autores, aquellos que ahora son tan celebrados. A Losada debemos los latinoamericanos nuestro permanente contacto con la lírica de Alberti. Si el exilio argentino fue duro para el poeta, la amistad con Losada y con tantos otros ciudadanos argentinos como Oliverio Girondo, Norah Lange, Roberto Arlt, fue un bálsamo para su nostalgia. Pasaría veinticuatro años en la tierra de 
Sarmiento y Lugones. En Pleamar escribiría para su hija Aitana frescos versos de particular intensidad y finura. Habría que remontarse al Ismaelillo de José Martí, dentro de la tradición castellana para encontrar palabras de tanta delicadeza sobre el sentimiento paternal:
Para ti, niña Aitana, remontando los ríos, este ramo de agua.
De agua dulce, ramito, que no de agua salada. Agua de azúcar, ramo. ramito, que no amarga. Remontando los ríos...

Si bien el destierro deja su marca indeleble de quienes los sufren, a un temperamento sensitivo, pero también cuajado en el conflicto político y en la dura lucha por la sobrevivencia en los años difíciles de la guerra civil española, le estimula la reflexión, el discurrir sosegado de la dicción poética. Así, utilizando el mar como motivo de inspiración directa, Alberti nos explica cuántas voces y cuán diferentes, están presentes en su estro, deambulan en sus versos. Nos entrega de manera indirecta una poética cuando nos dice:

Cantan en mí, maestro mar, metiéndose por los largos canales de mis huesos, olas tuyas que son olas maestras, vueltas a ti otra vez en un unido, mezclado y solo mar de mi garganta: Gil Vicente, Machado, Garcilaso, Baudelaire, Juan Ramón, Rubén Darío, Pedro Espinosa, Góngora... y las fuentes que dan voz a las plazas de mi pueblo.

Es un lírico dueño de su estro el que se dirige en una Carta abierta a los poetas, pintores, escritores.... de la España peregrina con estas palabras: 
No por pasar los años lejos de ti se olvida, España dura y dulce, que es tuya nuestra vida. Todo te lo debemos, y no podemos darte como pago la triste moneda de olvidarte. Cuando estás acosada y los que prisionera te venden, mantenidos por los perros de afuera; cuando el lobo avariento, de militar vestido, vive aún por la sangre de tu costado herido, las plumas que se callen, el lápiz que no grite, quien por ti no promueva, no proteste, no incite; quien el fuego de hoy no prenda hasta mañana, quien de espaldas soñando te espere a la ventana, madre del sufrimiento, vieja y joven leona, sientan en tu zarpazo tu ley que no perdona. Porque no merezcamos su furor y ese día. de su libertad suba de claro y alegría, joh errantes de la patria, oh del alba cercanos, la conciencia sin sombra, trabajemos, hermanos!

Alberti ha contado en Retornos de lo vivo lejano (1948-1956) cómo en aquellos años del destierro argentino, su lejana vida española se le perfilaba hasta en sus más mínimos detalles como recuerdos de lugares, personas, deseos, amores, tristezas, alegrías, cómo lo invadían hora a hora, haciendo del poema, no una elegía por las cosas ya muertas, sino por el contrario, una presencia viva, regresada, de las cosas que en el pasado no murieron sino que siguieron existiendo a pesar de su aparente lejanía. En el poema Retornos de una tarde con lluvia escribiría:

También estará ahora lloviendo, neblinando en aquellas bahías de mis muertes, de mis años aún vivos sin muertes. También por la neblina entre el pinar, lloviendo, lloviendo, y la tormenta también, los ya distantes truenos con gritos celebrados, últimos, el fustazo final del rayo por las torres. 
Y a Juan Ramón Jiménez le dedicaría estos versos de Retornos en un día de cumpleaños:

\author{
Subí yo aquella tarde \\ con mis primeros versos \\ a la sola azotea \\ donde entre madreselvas y jazmines \\ él en silencio ardía. \\ (...) \\ ¡Oh señalado tiempo! \\ El entonces tenía \\ la misma edad que hoy, \\ dieciséis de diciembre, \\ tengo yo aquí tan lejos \\ de aquella tarde pura \\ en la que le subí el mar \\ a su sola azotea.
}

Ha contado también Alberti que su libro Baladas y canciones del Paraná surgió frente a los bañados del inmenso río argentino, llenos de vacas y caballos, sobre unas altas barrancas de naranjos y de loros en las que se alzaba una casa misteriosa llamada la Quinta del Mayor loco, que había sido propiedad de un militar español que desapareció un día después que su mujer intentara matarlo por dos veces. Estas Baladas recuerdan los primeros momentos de Alberti, por su musicalidad expresada en el manejo diestro de los estribillos, en el conocimiento sabio de la tradición castellana, en ese medir y no medir los versos, que es la impronta, el sello, la marca de la poesía de nuestro vate. Dicho de otro modo: Alberti es uno de los más claros ejemplos en la poesía española de cómo un poeta puede ir y regresar del verso medido al verso libre y puede crear una zona personal, irrepetible, única, que satisfaga tanto a quienes admiran el alarde técnico de las sílabas contadas de un Garcilaso como a quienes se exaltan con el verso libérimo de un Vicente Aleixandre. Uno de los poemas más hermosos de esta época es la Balada del andaluz perdido: 
Perdido está el andaluz

del otro lado del río.

-Río, tú que conoces:

¿quién es y por qué se vino?

Vería los olivares

cerca tal vez de otro río.

-Río, tú que lo conoces:

¿qué hace siempre junto al río?

Vería el odio, la guerra, cerca tal vez de otro río.

-Río, tú que lo conoces:

¿qué hace solo junto al río?

Ve su rancho de adobe

del otro lado del río.

No veo los olivares

del otro lado del río.

Sólo caballos, caballos, caballos, solos, perdidos.

¡Soledad de un andaluz del oro lado del río!

¿Qué hará solo ese andaluz del otro lado del río?

En 1955 puede el poeta volver a Europa como un visitante, aunque todavía le estuvo vedado regresar a su España. Escribió entonces: 
¡Volverte a ver Europa, volver a verte!

Y al fin te he visto, y toda, toda tú me has mirado.

No me vieron tus ojos ya con ojos de muerte

sino con la alegría de un sol resucitado.

Bajé a ti desde un cielo de otoño una mañana.

Noviembre entre la bruma azul se deshacía.

Bélgica era una novia vestida de campana, tocada por el ángel de la melancolía.

En La primavera de los pueblos (1955-1968).

Pero el regreso definitivo a Europa ocurrió en 1964 y el lugar escogido fue Roma. Alberti llevaba lo itálico en la sangre, dos de sus abuelos habían sido de origen italiano, pero sus dos abuelas eran andaluzas de pura cepa. Su profesión había sido la de poeta, desterrado. En Roma, como en tantos otros lugares, metafóricamente, estaba y no estaba en su casa. En el soneto primero de Roma, peligro para caminantes (1964-1967), uno de los dedicó al poeta Guiseppe Gioacchino Belli, volvió el ángel de la melancolía a tensar su lira:

Dejé por ti mis bosques, mi perdida arboleda, mi perros desvelados, mis capitales años desterrados hasta casi el invierno de mi vida.

Dejé un temblor, dejé una sacudida, un resplandor de fuegos no apagados, dejé mi sombra en los desesperados ojos sangrantes de la despedida.

Dejé palomas tristes junto a un río, caballos sobre el sol de las arenas, dejé de ver la mar, dejé de verte. 
Dejé por ti todo lo que era mío,

Dame tú Roma, a cambio de mis penas, tanto como dejé para tenerte.

En este soneto no se sabe qué admirar más, si la perfección formal, expresada no sólo en lo bien medido de los versos, sino en la sabia distribución de los acentos o el hondo contenido de los versos que aluden a la ambivalencia de quien deja un lugar para afincarse en otro. Roma, hermosa, vieja y joven, no se entrega de un momento a otro al poeta, le hace sentir una vez más que es un desterrado. Así queda constancia en el Nocturno que dice:

De pronto en Roma no hay nadie:

no hay ni perro que me muerda

no hay ni gato que me arañe, no hay ni puerta que se abra, no hay ni balcón que me llame, no hay puente que me divise, no hay ni río que me arrastre, no hay ni foso que me hunda, no hay ni torre que me mate.

De pronto, Roma está sola, Roma está sola sin nadie.

Sabido es que a partir de su etapa romana, el poeta fue continuando distintas vetas de su estro, siendo una de las más conocidas, su nuevo acercamiento a la pintura. El exilio que había sido tan ingrato, también le permitió ser un ciudadano del mundo. Cabe, a partir de ese instante, es decir cuando llega a sentirse cómodo en Roma, considerarlo más que como un exiliado, como un poeta peregrino que va ganando no solamente madurez, sino sabiduría. Si bien Alberti, a lo largo de varias décadas de producción, nunca fue un poeta difícil, a pesar de que conocía bien el arte barroco, pareciera que a partir de los años sesenta tiene todavía más en cuenta los fueros del lector. Quiere llegar, no de una manera teórica, inspirada acaso en programas político-literarios, sino de forma clara y concisa a cualquier persona. Se ha convertido ya en un mago de palabra, 
en alguien que no exhibe sus recursos sino que muestra resultados. Por eso la imagen que más le conviene es la del poeta que va por el camino siguiendo la receta de Berceo, con un vaso de bon vino:

El poeta pide por las calles

Señores, para el camino

dadme un vaso de buen vino.

He venido gentilmente aquí, sin pediros nada, a hablaros valientemente como un poeta en la estrada tantos años peregrino.

Señores, para el camino dadme un vaso de buen vino.

Dadme un vaso y, si mejor os parece, una botella, poco a cambio de una flor, una paloma, una estrella, la fe en un grande destino.

Señores, para el camino dadme un vaso de buen vino.

Pobre soy para pedir, mas soy rico para daros, a los que queráis oír, la luz que puede salvaros de tanto oscuro asesino.

Señores, para el camino dadme un vaso de buen vino. 
Y también la lozanía

y el ejemplo que da el mar,

que con su caballería

se le ve siempre avanzar

en un solo torbellino.

Señores, para el camino

dadme un vaso de buen vino.

Vengo y voy, en la meta

de mi ruta ajetreada, como un perdido cometa

que entre el clavel y la espada

reaparece repentino.

Señores, para el camino

dadme un vaso de buen vino.

Dadme un vaso a condición

de que conmigo brindéis

y de que nunca olvidéis

el vino de esta canción, vino de mi corazón

que se va por donde vino.

Señores, para el camino

dadme un vaso de buen vino.

Vemos a Rafael Alberti como un poeta caminante, romero en su propia tierra, desde Cádiz hasta Madrid, hombre de sosiegos en su arboleda perdida, peregrino otra vez en América, en su Argentina, en Buenos Aires o a orillas del Paraná, andariego en Uruguay, distraído paseante por las calles de Roma, meditabundo, observando la vida de perros, gatos y aquella otra tan curiosa de la gente; lo miramos también como un leal admirador de la pintura, como un impenitente enamorado, 
como un poeta que al mismo tiempo es luchador contra todo tipo de injusticia y que ama las simplicidades de la vida.

Alberti se convirtió en imagen nítida de la España libertaria. Él expresa, junto con sus compañeros Lorca, Cernuda, Aleixandre, Hernández, Salinas, Guillén, algo de lo mejor de la lengua castellana. Vista en un solo haz, su poesía se interna en los meandros mismos del idioma, y pese a su aparente dispersión (que de otro lado le hace ganar tan disímiles lectores) tiene una constante que bien pueden admirar los eruditos: está hecha con un virtuosismo inusual en los poetas de hogaño. Sus versos conmueven, dejan temblando, expresan el dolor, pero son, sobre todo, un canto a la vida. Quede aquí constancia del agradecimiento de numerosos devotos lectores.

\section{BIBLIOGRAFÍA}

ALBERTI, Rafael. Obras completas. Madrid, Aguilar, 1988. Edición, introducción y notas de Luis García Montero.

. Cuadernos hispanoamericanos 485-486. Madrid, noviembrediciembre 1990.

\section{Correspondencia:}

Marco Martos Carrera

Presidente de la Academia Peruana de la Lengua.

Correo electrónico: marco.martos@academiaperuanadelalengua.org 